\title{
Impact of Head-of-Bed Posture on Brain Oxygenation in Patients with Acute Brain Injury: A Prospective Cohort Study
}

\author{
Laetitia Burnol ${ }^{1,2^{*}} \mathbb{0}$, Jean-Francois Payen ${ }^{3}$, Gilles Francony ${ }^{3}$, Kristina Skaare $^{4}$, Romain Manet ${ }^{5}$, Jérôme Morel ${ }^{2}$, \\ Jean-Luc Bosson ${ }^{4}$ and Laurent Gergele $\mathrm{e}^{1,2}$
}

(C) 2021 Springer Science+Business Media, LLC, part of Springer Nature and Neurocritical Care Society

\begin{abstract}
Background: Therapeutic head positioning plays a role in the management of patients with acute brain injury. Although intracranial pressure (ICP) is typically lower in an upright posture than in a flat position, limited data exist concerning the effect of upright positioning on brain oxygenation and circulation. We sought to determine the impact of supine $\left(0^{\circ}\right)$ and semirecumbent $\left(15^{\circ}\right.$ and $\left.30^{\circ}\right)$ postures on ICP, brain oxygenation, and brain circulation.

Methods: An observational cohort study was conducted between February 2012 and September 2015. Twentythree patients with severe acute brain injury were successively observed at head elevations of $30^{\circ}, 15^{\circ}$, and $0^{\circ}$. Postural-induced changes in ICP, cerebral perfusion pressure, brain tissue oxygenation pressure, and transcranial Doppler findings were simultaneously measured during three repeated experiments: $24 \mathrm{~h}$ after admission to the intensive care unit (exp1), $24 \mathrm{~h}$ later (exp2), and $96 \mathrm{~h}$ later (exp3). Cerebral perfusion pressure, arterial blood gases, hemoglobin content, and body temperature remained unchanged during the three experiments.

Results: Using linear random-slope mixed models, we found that during the early phase of acute brain injury (exp1), lowering the head posture from $30^{\circ}$ to $15^{\circ}$, and then to $0^{\circ}$, was associated with a gradual mean ICP increase of $2.6 \mathrm{~mm}$ $\mathrm{Hg}(1.4-3.7 \mathrm{~mm} \mathrm{Hg} ; P<0.001)$; and from $30^{\circ}$ to $0^{\circ}$, an increase of $7.4 \mathrm{~mm} \mathrm{Hg}(6.3-8.6 \mathrm{~mm} \mathrm{Hg} ; P<0.001)$. Furthermore, brain tissue oxygenation pressure and mean blood flow velocity improved when the head posture was lowered from $30^{\circ}$ to $0^{\circ}$ by $1.2 \mathrm{~mm} \mathrm{Hg}(0.2-2.3 \mathrm{~mm} \mathrm{Hg})$ and $4.1 \mathrm{~cm} / \mathrm{s}(0.0-8.2 \mathrm{~cm} / \mathrm{s})$, respectively (both $\left.P<0.05\right)$.

Conclusions: Changing the positioning of stable patients with acute brain injury resulted in opposite changes of ICP versus brain oxygenation and circulation. This information supports the concept of an individualized approach to head positioning that is based on the multimodal monitoring of brain parameters.
\end{abstract}

Keywords: Acute brain injury, Upright, Intracranial pressure, Cerebral circulation

\section{Introduction}

The management of patients with acute brain injury is directed toward the detection, prevention, and/or correction of secondary brain injury. Multimodal monitoring and treatments aim to lower intracranial pressure

\footnotetext{
${ }^{*}$ Correspondence: laetitia.burnol@gmail.com

1 Department of Anesthesiology and Critical Care, Ramsay Santé Private Hospital De La Loire, Saint-Etienne, France

Full list of author information is available at the end of the article
}

(ICP) and optimize brain perfusion [1]. Therapeutic head positioning plays a part in this management, as it may have beneficial effects on the brain physiology of these patients. The standard posture for patients who are critically ill is a semirecumbent position with head elevation at an angle of $30^{\circ}$. This allows for enteral nutrition to be administered, with reduced risks of silent gastric reflux and ventilator-associated pneumonia [2]. For decades, studies have shown that elevating the head of the bed can also lower ICP in patients with head injuries [3-5]. 
However, these postural effects on ICP are attenuated by concomitant changes in mean arterial blood pressure (MAP) that keep cerebral perfusion pressure (CPP) (in which $\mathrm{CPP}=\mathrm{MAP}-\mathrm{ICP}$ ) unchanged $[6,7]$ or even reduced [8].

There is a growing body of evidence that, alongside ICP and CPP optimization, brain oxygenation should be considered a target that can affect the outcome of patients with brain injury [9-11]. Brain oxygenation can be compromised when oxygen delivery to the brain tissue is reduced, e.g., in cases of reduced cerebral blood flow and/or reduced arterial oxygen content [12, 13]. These conditions could be aggravated when patients are in an upright position, considering its effect on pressure. However, limited data exist about the effects of head posture on concomitant cerebral blood flow, brain oxygenation, ICP, and CPP measurements after acute brain injury. In patients with traumatic brain injury (TBI), elevating the head from $0^{\circ}$ (supine position) to $30^{\circ}$ significantly decreased ICP and was associated with no change in brain oxygenation, as indicated by jugular bulb venous oxygen saturation and/or brain tissue oxygenation pressure $\left(\mathrm{PbtO}_{2}\right)[3,6,14]$. In patients with large hemispheric stroke, a change in head elevation from $0^{\circ}$ to $30^{\circ}$ was associated with a reduction in both ICP and mean blood flow velocity $(\mathrm{FVm})$ of the affected hemisphere [15]. In these studies, measurements were performed only once, even though cerebral hemodynamics may change over time after acute brain injury. In addition, a head elevation of $30^{\circ}$ was the only upright posture compared with the supine position.

Because of the complex interplay between ICP, brain oxygenation, brain circulation, and degrees of head elevation, as well as the timing of these measurements, we conducted a cohort study in which the ICP, CPP, $\mathrm{PbtO}_{2}$, and transcranial Doppler findings of patients with acute brain injury were simultaneously monitored. Monitoring occurred when patients' head elevations were at $30^{\circ}$, $15^{\circ}$, and $0^{\circ}$ at three times during their stay in the intensive care unit (ICU). We hypothesized that during the early phase of acute brain injury, a $30^{\circ}$ upright posture could be detrimental to brain oxygenation and circulation. We also studied a subgroup of patients who underwent a decompressive craniectomy to investigate whether these potential effects could be affected by changes in brain compliance.

\section{Methods}

This prospective cohort study was conducted between February 2012 and September 2015 in the ICUs of two French university hospitals in Saint-Etienne and Grenoble, which had 23 general ICU beds and 9 neurological ICU beds, respectively. The Institutional Review Board of Saint-Etienne (Chairperson Professor P. Rusch; SaintEtienne University Hospital, Saint-Etienne, France) approved the study design on December 26, 2011 (ref. 2011-A01565-36). Written informed consent was obtained from patients' relatives before inclusion, when possible, or from a legally authorized representative. Informed consent was obtained from all individual participants included in the study. The study was retrospectively registered on September 15, 2015, at ClinicalTrials. gov (identifier NCT02549313).

\section{Patients}

Adult patients admitted to the ICU for acute brain injury, i.e., traumatic, vascular, or other injury, were managed according to international guidelines [16]. Patients were considered for study participation if their ICP was monitored with an intraparenchymal ICP device (Codman Microsensor ICP Transducer; Codman, Saint Priest, France; Johnson \& Johnson, Issy-les-Moulineaux, France; or Sophysa Pressio, Orsay, France). The physician in charge determined whether the patient also required a $\mathrm{PbtO}_{2}$ probe to be inserted (Licox; Integra Lifesciences, Saint Priest, France) to monitor brain oxygenation. A $\mathrm{PbtO}_{2}$ probe was inserted into the least injured hemisphere, or in the contralateral side in cases of hemispheric stroke. Noninclusion criteria were the persistence of hemodynamic or respiratory instability despite treatments, severe brain hypoxia (defined as $\mathrm{PbtO}_{2}$ less than $15 \mathrm{~mm} \mathrm{Hg}$ ) or refractory intracranial hypertension (defined as ICP more than $30 \mathrm{~mm} \mathrm{Hg}$ ) at baseline, the development of cerebral vasospasm, and no cerebral monitoring of ICP and $\mathrm{PbtO}_{2}$.

Patients were continuously sedated with propo$\mathrm{fol} /$ midazolam and sufentanil/remifentanil and were mechanically ventilated to obtain normocapnia (partial pressure of carbon dioxide, arterial $\left[\mathrm{PaCO}_{2}\right] 35-40 \mathrm{~mm}$ $\mathrm{Hg}$ ) and normoxia (partial pressure of oxygen, arterial $\left[\mathrm{PaO}_{2}\right]$ 80-120 mm $\mathrm{Hg}$ ) status. Normothermia $\left(36-37^{\circ} \mathrm{C}\right)$ was maintained using blankets or ice packs on the femoral region, and the patients were maintained in normal ranges of serum glucose $(7-10 \mathrm{mmol} / \mathrm{L})$ and sodium (135-145 mmol/L). CPP was kept between 60 and $70 \mathrm{~mm} \mathrm{Hg}$ via a vasoactive support with norepinephrine and, if needed, plasma volume expansion with crystalloids. Normal cardiac function and normovolemic status were demonstrated using echocardiography (left ventricular ejection fraction of more than 55\%), central venous pressure (more than $5 \mathrm{~cm} \mathrm{H}_{2} \mathrm{O}$ ), and spontaneous urine output (more than $0.5 \mathrm{ml} / \mathrm{kg} /$ hour) measurements.

\section{Ethical Approval}

All procedures performed in studies involving human participants were in accordance with the ethical 
standards of the Institutional Review Board of SaintEtienne and with the 1964 Declaration of Helsinki and its later amendments or comparable ethical standards.

\section{Study Protocol and Measurements}

All patients were initially positioned in a $30^{\circ}$ head-up posture, with the head in a neutral, nonflexed, or rotated position in relation to the torso. The degree of head elevation was controlled by a goniometer and an adjustable electric bed. After $10 \mathrm{~min}$ of stabilization in the position, each systemic and brain parameter was recorded three times during 5-min time periods, and the values were averaged. Patients' head elevations were subsequently lowered to $15^{\circ}$ and $0^{\circ}$ positions in a nonrandomized sequential order, and variables were recorded in a similar time line. During these experiments, there was no change in the administration of sedative drugs or the ventilator setting. If the patient was receiving norepinephrine, the drug dose was adjusted to keep CPP unchanged, i.e., within $60-70 \mathrm{~mm} \mathrm{Hg}$. The first experiments were initiated once the patient was monitored with ICP and $\mathrm{PbtO}_{2}$ probes, i.e., $24 \mathrm{~h}$ after admission to the ICU (exp1), and then repeated $24 \mathrm{~h}(\exp 2)$ and $96 \mathrm{~h}$ later $(\exp 3)$. If the patient exhibited a decrease in MAP of more than $15 \%$ from baseline, an ICP exceeding $30 \mathrm{~mm} \mathrm{Hg}$, or a $\mathrm{PbtO}_{2}$ below $15 \mathrm{~mm} \mathrm{Hg}$ during the posture change, the ongoing experiment was interrupted and the patient was repositioned.

Variables included patient characteristics and brain parameters collected every $5 \mathrm{~min}$, i.e., mean ICP, CPP, and $\mathrm{PbtO}_{2}$ measurements. $\mathrm{FVm}$, systolic blood flow velocity (FVs), and diastolic blood flow velocity (FVd) over 5-s recordings were measured in each of the two middle cerebral arteries using 2D Doppler ultrasonography (Philips CX50; Philips HealthSystems, Suresnes, France). Pulsatility index $(\mathrm{PI})$ was calculated as $\mathrm{PI}=(\mathrm{FVs}-\mathrm{FVd}) / \mathrm{FVm}$. Measurements of blood gases $\left(\mathrm{PaO}_{2}\right.$ and $\left.\mathrm{PaCO}_{2}\right)$ were also collected during each head positioning. Because the calculation of CPP can be markedly affected by whether MAP is measured at the level of the right atrium or at the level of the foramen of Monro [17, 18], we used MAP measurements obtained at the foramen of Monro at both a $30^{\circ}$ and $15^{\circ}$ head elevation. The Glasgow Outcome Scale score was determined at discharge from the ICU, ranging from 1 (dead) to 5 (good recovery).

\section{Statistical Analysis}

We estimated that 20 patients would be needed to detect a $25 \%$ posture-induced change from baseline in $\mathrm{PbtO}_{2}$ values with a two-sided $\alpha$ risk of 0.05 and a power of $90 \%$. Continuous variables were expressed as median and interquartile range (25-75th percentile), and categorical variables were expressed as frequencies and percentages, unless stated otherwise. Statistical significance was declared when $P<0.05$ (Stata 15.1; Stata Corporation, College Station, TX). The variables $\mathrm{PbtO}_{2}, \mathrm{ICP}, \mathrm{CPP}$, $\mathrm{PI}$, and FVm were analyzed using linear random-slope mixed models to account for repeated measures. The mixed-effects models included the experiments (exp2 or exp3 versus exp1 as reference), the sequential order of the three head postures $\left(30^{\circ}\right.$ to $15^{\circ}$ to $0^{\circ}$ versus $30^{\circ}$ to $0^{\circ}$ to $15^{\circ}$ as reference), the degree of head elevation $\left(0^{\circ}\right.$ or $15^{\circ}$ versus $30^{\circ}$ as reference), and decompressive craniectomy (present versus absent as reference) as covariate fixed effects. Interactions between covariates were included in the model if they were statistically significant and clinically relevant. The other variables were compared using the nonparametric Wilcoxon signed-rank test for paired data, the Friedman test for repeated measurements, and Bonferroni's correction for multiple comparisons.

\section{Results}

Twenty-three patients with acute brain injury were included consecutively in the two sites. Table 1 displays their characteristics. Severe presentation, i.e., with an initial Glasgow Coma Scale score less than 9, was found in 16 patients with TBI, 3 patients with subarachnoid hemorrhage, and 3 patients with stroke. Ten patients, including five with TBI, had early decompressive craniectomy due to refractory intracranial hypertension, despite

\section{Table 1 Characteristics of the 23 patients}

\begin{tabular}{ll} 
Variables & $\mathbf{N}=\mathbf{2 3}$ \\
\hline Age (years) & $37(32-48)$ \\
Male sex, $n(\%)$ & $18(78)$ \\
Weight (kg) & $73(69-86)$ \\
Glasgow Coma Scale score on admission & $6(5-10)$ \\
Cause of brain injury, $n$ (\%) & \\
Traumatic brain injury & $16(70)$ \\
Subarachnoid hemorrhage & $3(13)$ \\
Stroke & $3(13)$ \\
Other & $1(4)$ \\
APACHE score on admission & $44(41-55)$ \\
SOFA score on admission & $9(8-11)$ \\
Decompressive craniectomy, $n$ (\%) & $10(44)$ \\
Outcome on day 28, $n$ (\%) & \\
Death & $4(17)$ \\
Still in ICU & $12(52)$ \\
\hline Transferred to surgical or medical ward & $3(13)$ \\
\hline Transferred to rehabilitation unit & $4(17)$ \\
Glasgow Outcome Scale score at discharge from the ICU & $4(2-4)$ \\
\hline
\end{tabular}

Data are expressed as median (25-75th percentile) unless otherwise specified APACHE, Acute Physiology and Chronic Health Evaluation; ICU, intensive care unit; SOFA, Sequential Organ Failure Assessment 
medical therapies. The median delay from injury to the placement of intracerebral probes was $24 \mathrm{~h}(10-24 \mathrm{~h})$. Exp1 was initiated during the first $24 \mathrm{~h}$ after admission to the ICU. There were 18,21 , and 15 patients who had complete data for exp1, exp2, and exp3, respectively. Missing data were related to neurologic or respiratory intolerance, technical problems with $\mathrm{PbtO}_{2}$ measurements, evolution toward brain death, or a rapid improvement in the patient's condition, allowing awakening. No ongoing experiment was interrupted because of compromised brain homeostasis.

Table 2 shows the effects of the three head positions on systemic and brain variables during exp1, exp2, and exp3 after admission to the ICU. CPP, arterial blood gases, hemoglobin content, and body temperature remained unchanged during the three experiments. In exp1 and exp2, norepinephrine doses were significantly lower at a head elevation of $0^{\circ}$ than at a head elevation of $30^{\circ}$ (both $P<0.05)$. According to the linear mixed models, upright posture and experiments had significant effects on ICP, $\mathrm{PbtO}_{2}$, and brain circulation (PI and FVm; Table 3). During exp1, lowering the head from $30^{\circ}$ to $15^{\circ}$ and $0^{\circ}$ was associated with a gradual elevation in ICP, with a mean increase of $2.6 \mathrm{~mm} \mathrm{Hg}(1.4-3.7 ; P<0.001)$ from $30^{\circ}$ to $15^{\circ}$ and of $7.4 \mathrm{~mm} \mathrm{Hg}(6.3-8.6 \mathrm{~mm} \mathrm{Hg} ; P<0.001)$ from $30^{\circ}$ to $0^{\circ}$. In addition, $\mathrm{PbtO}_{2}$ and $\mathrm{FVm}$ improved from $30^{\circ}$ to $0^{\circ}$ by $1.2 \mathrm{~mm} \mathrm{Hg}(0.2-2.3 \mathrm{~mm} \mathrm{Hg})$ and $4.1 \mathrm{~cm} / \mathrm{s}(0.0-$ $8.2 \mathrm{~cm} / \mathrm{s}$ ), respectively (both $\mathrm{P}<0.05$ ). $\mathrm{PbtO}_{2}$ and $\mathrm{FVm}$ were significantly higher during exp2 than exp1. Neither decompressive craniectomy nor the order in which the head position was changed affected brain parameters.

\section{Discussion}

In this study, we used a multivariate analysis to study the effect of head position and timing of measurements on brain parameters in stable patients with acute brain injury. During the early phase of acute brain injury, lowering the elevation of a patient's head from $30^{\circ}$ to $15^{\circ}$ and $0^{\circ}$ was associated with a gradual increase in ICP and improved measurements of brain oxygenation and circulation. Although limited in their amplitude, changes in these brain parameters were observed in stable patients with no severe brain hypoxia or refractory intracranial hypertension. In a higher-risk patient population, caution should be exercised when positioning a patient's head at a $30^{\circ}$ elevation during the early phase of acute brain injury, unless brain oxygenation and/or circulation has been directly measured. Interindividual variability was also observed, making the expected effects of head positioning on brain parameters difficult to predict for all patients and favoring an individualized approach to head positioning.

Table 2 Effects of head elevations of $30^{\circ}, 15^{\circ}$, and $0^{\circ}$ (flat) on systemic and brain variables during the three experiments (exp1, exp2, and exp3) after admission to the ICU

\begin{tabular}{|c|c|c|c|c|c|c|c|c|c|}
\hline \multirow{2}{*}{$\begin{array}{l}\text { Variables } \\
\text { Head posture }\left({ }^{\circ}\right)\end{array}$} & \multicolumn{3}{|l|}{ Exp1 } & \multicolumn{3}{|l|}{ Exp2 } & \multicolumn{3}{|l|}{ Exp3 } \\
\hline & 30 & 15 & 0 & 30 & 15 & 0 & 30 & 15 & 0 \\
\hline $\begin{array}{l}\text { MAP, right atrium } \\
(\mathrm{mm} \mathrm{Hg})\end{array}$ & 91 (83-98) & $90(81-94)$ & 90 (82-97) & $85(80-101)$ & $85(79-102)$ & $83(76-101)$ & $86(81-100)$ & $83(81-100)$ & 83 (80-98) \\
\hline $\begin{array}{l}\text { MAP, Monro (mm } \\
\mathrm{Hg})\end{array}$ & $82(75-94)$ & 83 (79-94) & $90(81-100)$ & $81(72-92)$ & 81 (75-99) & 83 (77-99) & 80 (72-93) & $81(75-95)$ & $83(80-98)$ \\
\hline ICP (mm Hg) & $15(11-18)$ & $15(12-22)$ & $22(16-26)$ & $15(10-18)$ & $16(13-21)$ & $18(17-24)$ & $13(9-18)$ & $16(12-22)$ & $20(17-26)$ \\
\hline CPP $(\mathrm{mm} \mathrm{Hg})$ & 70 (60-75) & 70 (60-75) & 70 (60-75) & $65(63-75)$ & $65(64-75)$ & $65(63-71)$ & $65(59-80)$ & $69(59-80)$ & $66(59-80)$ \\
\hline $\mathrm{PbtO}_{2}(\mathrm{~mm} \mathrm{Hg})$ & $22(17-28)$ & $24(18-30)$ & $25(21-31)$ & $25(22-30)$ & 25 (23-29) & $25(23-29)$ & $27(25-30)$ & $27(25-30)$ & $28(26-31)$ \\
\hline $\mathrm{FVm}(\mathrm{cm} / \mathrm{s})$ & $58(47-87)$ & $58(51-82)$ & 60 (52-94) & $73(63-109)$ & $79(65-101)$ & $80(71-111)$ & $74(64-83)$ & 74 (59-91) & $71(65-91)$ \\
\hline $\mathrm{FVd}(\mathrm{cm} / \mathrm{s})$ & $36(27-51)$ & $35(30-58)$ & 35 (29-64) & $41(33-65)$ & $47(35-69)$ & $52(43-74)$ & $48(36-58)$ & $43(39-56)$ & $43(38-56)$ \\
\hline $\mathrm{PI}$ & $1.1(0.8-1.5)$ & $1.1(0.7-1.6)$ & $1.0(0.7-1.3)$ & $1.2(0.5-1.6)$ & $1.1(0.5-1.8)$ & $1.0(0.6-1.6)$ & $1.1(0.6-1.7)$ & $1.1(0.6-1.7)$ & $1.2(0.6-1.8)$ \\
\hline $\mathrm{PaO}_{2}(\mathrm{~mm} \mathrm{Hg})$ & $104(93-122)$ & $105(95-124)$ & $106(91-119)$ & $98(82-116)$ & $97(82-119)$ & $97(82-120)$ & $107(101-118)$ & $112(99-124)$ & $114(95-132)$ \\
\hline $\mathrm{PaCO}_{2}(\mathrm{~mm} \mathrm{Hg})$ & $38(35-40)$ & $37(34-39)$ & $37(35-38)$ & $39(37-41)$ & $38(37-42)$ & $38(36-42)$ & $37(35-41)$ & $38(35-41)$ & $38(35-41)$ \\
\hline $\begin{array}{l}\text { Hemoglobin } \\
(\mathrm{g} / \mathrm{dl})\end{array}$ & $11(10-12)$ & $11(10-12)$ & $11(10-12)$ & $11(10-12)$ & $11(10-12)$ & $11(9-12)$ & $10(9-11)$ & $10(9-11)$ & $10(9-11)$ \\
\hline Temperature $\left({ }^{\circ} \mathrm{C}\right)$ & $37(35-37)$ & $36(35-37)$ & $36(35-37)$ & $37(36-38)$ & $37(36-37)$ & $37(36-37)$ & $37(36-38)$ & $37(36-38)$ & $37(36-38)$ \\
\hline $\begin{array}{l}\text { Norepinephrine } \\
(\mu \mathrm{g} / \mathrm{kg} / \mathrm{h})\end{array}$ & $16(5-31)$ & $13(6-31)$ & $12(6-26)$ & $21(7-33)$ & $19(7-31)$ & $12(5-43)$ & $16(6-26)$ & $13(5-26)$ & $15(5-26)$ \\
\hline
\end{tabular}

Experiments were performed $24 \mathrm{~h}$ after admission to the ICU (exp1), and then repeated $24 \mathrm{~h}$ (exp2) and $96 \mathrm{~h}$ later (exp3). Data are expressed as median (25-75th percentile). See text for statistically significant results

CPP, cerebral perfusion pressure; FVd, diastolic blood flow velocity; FVm, mean blood flow velocity; ICP, intracranial pressure; ICU, intensive care unit; MAP, mean arterial pressure; $\mathrm{PaCO}_{2}$, partial pressure of carbon dioxide, arterial; $\mathrm{PaO}_{2}$, partial pressure of oxygen, arterial; $\mathrm{PbtO} \mathrm{O}_{2}$, brain tissue oxygenation pressure; $\mathrm{PI}$, pulsatility index 
Table 3 Linear random-slope mixed models for $\mathrm{PbtO}_{2}$, ICP, CPP, PI, and FVm

\begin{tabular}{|c|c|c|c|c|c|}
\hline & $\mathrm{PbtO}_{2}(\mathrm{~mm} \mathrm{Hg})$ & ICP $(\mathrm{mm} \mathrm{Hg})$ & CPP (mm Hg) & PI & $\mathrm{FVm}(\mathrm{cm} / \mathrm{s})$ \\
\hline Measurements (n) & 167 & 158 & 158 & 167 & 167 \\
\hline \multicolumn{6}{|l|}{ Fixed effects parameters } \\
\hline Exp2 & $2.6(0.7 \text { to } 4.5)^{* *}$ & $0.8(-1.9$ to 3.5$)$ & $-0.2(-3.1$ to 2.6$)$ & $0.0(-0.1$ to 0.1$)$ & $18.1(13.1 \text { to } 23.0)^{* *}$ \\
\hline Exp3 & $4.8(-1.4$ to 11.0$)$ & $4.6(-5.3$ to 14.5$)$ & $-1.1(-7.4$ to 5.3$)$ & $0.2(0.0 \text { to } 0.4)^{*}$ & $3.7(-7.5$ to 14.9$)$ \\
\hline $30^{\circ}$ to $15^{\circ}$ to $0^{\circ}$ order & $-2.2(-5.7$ to 1.3$)$ & $4.3(-1.2$ to 9.9$)$ & $7.8(1.7 \text { to } 13.8)^{*}$ & 0.1 ( -0.0 to 0.3$)$ & $-4.6(-25.6$ to 16.5$)$ \\
\hline $0^{\circ}$ position & $1.2(0.2 \text { to } 2.3)^{*}$ & $7.4(6.3 \text { to } 8.6)^{* *}$ & $-0.4(-2.9$ to 2.0$)$ & $-0.1(-0.1 \text { to }-0.0)^{* *}$ & $4.1(0.0 \text { to } 8.2)^{*}$ \\
\hline $15^{\circ}$ position & $0.6(-0.5$ to 1.6$)$ & $2.6(1.4 \text { to } 3.7)^{* *}$ & $0.0(-2.5$ to 2.5$)$ & $-0.0(-0.1 \text { to } 0.00)^{*}$ & $2.3(-1.8$ to 6.4$)$ \\
\hline Decompressive craniectomy & $-2.9(-6.4$ to 0.6$)$ & $-4.0(-9.7$ to 1.6$)$ & $5.0(-1.1$ to 11.2$)$ & $0.0(-0.2$ to 0.2$)$ & $-4.6(-25.8$ to 16.6$)$ \\
\hline Constant & 25.7 (21.7 to 29.7) & $12.9(8.0$ to 17.8$)$ & $61.7(55.9$ to 67.5$)$ & $1.0(0.8$ to 1.2$)$ & 71.3 (51.6 to 91.1) \\
\hline
\end{tabular}

Each model includes covariate fixed effects, i.e., the experiments (exp2 or exp3 versus exp 1 ), the sequential order of the three head postures ( $30^{\circ}$ to $15^{\circ}$ to $0^{\circ}$ versus $30^{\circ}$ to $0^{\circ}$ to $\left.15^{\circ}\right)$, the degree of head elevation $\left(0^{\circ}\right.$ or $15^{\circ}$ versus $\left.30^{\circ}\right)$, and the decompressive craniectomy (present versus absent). Covariance coefficients are expressed as mean ( $95 \%$ confidence interval)

CPP, cerebral perfusion pressure, exp1, performed $24 \mathrm{~h}$ after admission to the ICU, exp2, repeated $24 \mathrm{~h}$ later, exp3, repeated $96 \mathrm{~h}$ later; ICP intracranial pressure; $\mathrm{FVm}$, mean blood flow velocity; $\mathrm{PbtO}_{2}$, oxygenation pressure, $\mathrm{Pl}$, pulsatility index

${ }^{*} P<0.05$ compared to covariate at baseline; ${ }^{* *} P<0.001$ compared to covariate at baseline

Although positioning patients in an upright $30^{\circ}$ posture is a common practice in the ICU, recent guidelines do not provide guidance on optimal head positioning for the management of patients with acute traumatic or nonTBI [19-22]. This could be due to inconsistency in the literature and/or the negligible impact of head position on neurological outcome. This latter point was recently addressed in a trial that revealed no difference in the neurological outcomes after acute stroke between patients positioned in a flat posture and those positioned in a $30^{\circ}$ upright posture [23]. In addition, the complex interplay between ICP, brain oxygenation, and circulation, as well as the timing of measurements, required appropriate statistics (i.e., linear random-slope mixed models), which were not used in previous studies $[3,6,14,15]$.

Using a multivariate approach, we confirmed that ICP is markedly affected by head posture, independent from the timing of measurements. ICP was lower when patients were in an upright position than when they were in a flat position, as reported elsewhere $[3-5,14$, 24 ]. This effect was proportionally related to the degree of head elevation. The effect of the flat position on ICP could be explained by the redistribution of intracranial venous blood to lower parts of the body, i.e., a reduced cerebral blood volume, or by cerebrospinal fluid redistribution to the spinal subarachnoid space. This second hypothesis is probably the most prominent mechanism; the creation of a hydrostatic pressure gradient in an upright posture allows cerebrospinal fluid to circulate from the cranial to the spinal space $[25,26]$. In such a model, the cerebrospinal fluid pressure behaves according to the law of fluid mechanics. On the other hand, no major changes in cerebral blood volume are observed in volunteers after standing from a supine position [27].
Accordingly, we found that decompressive craniectomy had no effect on these postural-induced ICP changes, even though decompressive craniectomy can reduce cerebral blood volume [28].

In our stable patients, we found transient, but significant, differences in brain oxygenation and brain circulation between the two head elevations $\left(30^{\circ}\right.$ and $\left.0^{\circ}\right)$. This occurred while all systemic factors that can alter $\mathrm{PbtO}_{2}$ measurements were normalized or kept unchanged during the experiments, e.g., sedation, CPP, $\mathrm{PaCO}_{2}, \mathrm{PaO}_{2}$, hemoglobin content, and temperature $[12,13]$. No patient showed evidence of cardiac failure or hypovolemia. The significant reduction in norepinephrine doses between $30^{\circ}$ and $0^{\circ}$ to keep CPP within $60-70 \mathrm{~mm} \mathrm{Hg}$ could be due to the disappearance of the hydrostatic column created by upright posture with MAP measurements obtained at the foramen of Monro.

In the study by $\mathrm{Ng}$ et al. [14], which found that $\mathrm{PbtO}_{2}$ values did not differ significantly by head elevation, $\mathrm{PbtO}_{2}$ measurements ranged from 6 to $100 \mathrm{~mm} \mathrm{Hg}$ at a $0^{\circ}$ head elevation and from 4 to $92 \mathrm{~mm} \mathrm{Hg}$ at a $30^{\circ}$ head elevation, making it difficult to draw any conclusions about the true effects of head positioning. In the present study, FVm was higher in a flat position than at a $30^{\circ}$ head elevation, as observed previously [15]. This may reflect increased brain perfusion in a flat position. Interestingly, $\mathrm{PbtO}_{2}$ and $\mathrm{FVm}$ measurements were significantly improved in exp2 compared with exp1, as if a cerebral hyperemic reaction developed without affecting ICP. Again, no changes in systemic parameters or drug administration were observed during exp2. Therefore, these changes might reflect a temporal course of brain perfusion after brain injury that includes an initial phase of hypoperfusion, followed by a hyperemic 
phase [29]. These findings underscore the importance of the timing of measurements taken after acute brain injury.

Our study has several limitations. First, the number of included patients is relatively small $(n=23)$, although it might be offset by the number of assessments collected $(n=158-167)$. Second, these experiments were performed in stable patients with no evidence of severe brain hypoxia or uncontrolled intracranial hypertension. Our findings, therefore, need to be validated in patients with more severe conditions. Indeed, previous studies have reached opposite conclusions regarding the impact of head elevation on brain perfusion in patients with high ICP versus low ICP at baseline [6, 8]. Accordingly, head positioning to control ICP should be viewed as a means to restoring brain perfusion and then adjusted according to the results of a direct measurement of brain oxygenation and/or circulation. Third, our patients had various brain injuries, although the majority had TBI. The specific role of the nature, localization, and volume of brain lesions on head-posture-related changes is unknown. Fourth, we did not measure the cerebral autoregulation status during each experiment. We can only formulate conjectures to explain the attenuated effect of head elevation on norepinephrine doses in exp3; this could be mediated through an improvement of cerebral compliance and/or recovery of cerebral autoregulation at a later phase of brain injury. Fifth, there were no simultaneous, beat-by-beat measurements of ICP, CPP, $\mathrm{PbtO}_{2}$, and FVm during the experiments along with the use of specific software, preventing us from determining other indexes, such as critical closing pressure.

\section{Conclusions}

In conclusion, changing the positioning of stable patients with acute brain injury from a head elevation of $30^{\circ}$ to $15^{\circ}$ and $0^{\circ}$ resulted in a significant gradual increase in ICP. Concomitantly, even if the differences were minor, brain oxygenation and brain circulation were improved at a head elevation of $0^{\circ}$ during the early phase of brain insult. Because interindividual variability exists in brain parameters over time after acute brain injury, an individualized approach to head positioning should be favored.

\footnotetext{
Author details

${ }^{1}$ Department of Anesthesiology and Critical Care, Ramsay Santé Private Hospital De La Loire, Saint-Etienne, France. ${ }^{2}$ Department of Anesthesiology and Critical Care, University Hospital of Saint-Etienne, Saint-Etienne, France. ${ }^{3}$ Department of Anesthesiology and Critical Care, Grenoble Alpes University Hospital, Grenoble, France. ${ }^{4}$ Department of Public Health, Grenoble Alpes University Hospital, Grenoble, France. ${ }^{5}$ Department of Neurosurgery B, University Hospital of Lyon, Lyon, France.
}

\section{Author contributions}

J-FP contributed to conception and design of project critically revised, interpretation of data, drafting and critically revising manuscript for intellectual content and has approved the final version of manuscript. GF contributed to conception and design of project, acquisition and interpretation of data. KS contributed to interpretation of data and has approved the final version of manuscript. RM contributed to interpretation of data, critically revising manuscript for intellectual content and has approved the final version of manuscript. JM contributed to interpretation of data, critically revising manuscript for intellectual content and has approved the final version of manuscript. J-LB contributed to interpretation of data and has approved the final version of manuscript. LG contributed to conception and design of project critically revised, acquisition and interpretation of data, drafting and critically revising manuscript for intellectual content and has approved the final version of manuscript.

\section{Source of support}

No funding was received for this research.

\section{Conflicts of interest}

All authors certify that they have no affiliations with or involvement in any organization or entity with any financial interest (such as honoraria; educational grants; participation in speakers' bureaus; membership, employment, consultancies, stock ownership, or other equity interest; and expert testimony or patent-licensing arrangements) or nonfinancial interest (such as personal or professional relationships, affiliations, knowledge, or beliefs) in the subject matter or materials discussed in this article.

\section{Ethical approval/informed consent}

All procedures performed in studies involving human participants were in accordance with the ethical standards of the Institutional Review Board of Saint-Etienne and with the 1964 Declaration of Helsinki and its later amendments or comparable ethical standards.

\section{Clinical trial registration}

ClinicalTrials.gov: NCT02549313.

\section{Publisher's Note}

Springer Nature remains neutral with regard to jurisdictional claims in published maps and institutional affiliations.

Received: 16 November 2020 Accepted: 20 March 2021 Published online: 26 July 2021

\section{References}

1. Kirkman MA, Smith M. Intracranial pressure monitoring, cerebral perfusion pressure estimation, and ICP/CPP-guided therapy: a standard of care or optional extra after brain injury? Br J Anaesth. 2014;112:35-46.

2. Drakulovic MB, Torres A, Bauer TT, Nicolas JM, Nogue S, Ferrer M. Supine body position as a risk factor for nosocomial pneumonia in mechanically ventilated patients: a randomised trial. Lancet. 1999;354:1851-8.

3. Feldman Z, Kanter MJ, Robertson CS, Contant CF, Hayes C, Sheinberg MA, et al. Effect of head elevation on intracranial pressure, cerebral perfusion pressure, and cerebral blood flow in head-injured patients. J Neurosurg. 1992;76:207-11.

4. Kenning JA, Toutant SM, Saunders RL. Upright patient positioning in the management of intracranial hypertension. Surg Neurol. 1981;15:148-52.

5. Ropper AH, O'Rourke D, Kennedy SK. Head position, intracranial pressure, and compliance. Neurology. 1982;32:1288-91.

6. Meixensberger J, Baunach S, Amschler J, Dings J, Roosen K. Influence of body position on tissue-pO2, cerebral perfusion pressure and intracranial pressure in patients with acute brain injury. Neurol Res. 1997;19:249-53.

7. Petersen LG, Petersen JC, Andresen M, Secher NH, Juhler M. Postural influence on intracranial and cerebral perfusion pressure in ambulatory neurosurgical patients. Am J Physiol Regul Integr Comp Physiol. 2016;310:R100-4 
8. Rosner MJ, Coley IB. Cerebral perfusion pressure, intracranial pressure, and head elevation. J Neurosurg. 1986;65:636-41.

9. Chang JJ, Youn TS, Benson D, Mattick H, Andrade N, Harper CR, et al. Physiologic and functional outcome correlates of brain tissue hypoxia in traumatic brain injury. Crit Care Med. 2009;37:283-90.

10. Maloney-Wilensky E, Gracias V, Itkin A, Hoffman K, Bloom S, Yang W, et al. Brain tissue oxygen and outcome after severe traumatic brain injury: a systematic review. Crit Care Med. 2009;37:2057-63.

11. Oddo M, Levine JM, Mackenzie L, Frangos S, Feihl F, Kasner SE, et al. Brain hypoxia is associated with short-term outcome after severe traumatic brain injury independently of intracranial hypertension and low cerebral perfusion pressure. Neurosurgery. 2011;69:1037-45.

12. Bouzat P, Sala N, Payen JF, Oddo M. Beyond intracranial pressure: optimization of cerebral blood flow, oxygen, and substrate delivery after traumatic brain injury. Ann Intensive Care. 2013;3:23.

13. Rosenthal G, Hemphill JC 3rd, Sorani M, Martin C, Morabito D, Obrist WD, et al. Brain tissue oxygen tension is more indicative of oxygen diffusion than oxygen delivery and metabolism in patients with traumatic brain injury. Crit Care Med. 2008;36:1917-24.

14. Ng I, Lim J, Wong HB. Effects of head posture on cerebral hemodynamics: its influences on intracranial pressure, cerebral perfusion pressure, and cerebral oxygenation. Neurosurgery. 2004;54:593-7.

15. Schwarz S, Georgiadis D, Aschoff A, Schwab S. Effects of body position on intracranial pressure and cerebral perfusion in patients with large hemispheric stroke. Stroke. 2002;33:497-501.

16. Bratton SL, Chestnut RM, Ghajar J, McConnell Hammond FF, Harris OA, Hartl R, et al. Guidelines for the management of severe traumatic brain injury. J Neurotrauma. 2007;24(Suppl 1):S7-95.

17. Kosty JA, LeRoux PD, Levine J, Park S, Kumar MA, Frangos S, et al. Brief report: a comparison of clinical and research practices in measuring cerebral perfusion pressure: a literature review and practitioner survey. Anesth Analg. 2013;117:694-8.

18. Rao V, Klepstad P, Losvik OK, Solheim O. Confusion with cerebral perfusion pressure in a literature review of current guidelines and survey of clinical practice. Scand J Trauma Resusc Emerg Med. 2013;21:78.

19. Carney N, Totten AM, O'Reilly C, Ullman JS, Hawryluk GW, Bell MJ, et al. Guidelines for the management of severe traumatic brain injury, fourth edition. Neurosurgery. 2017:80:6-15.

20. Connolly Jr ES, Rabinstein AA, Carhuapoma JR, Derdeyn CP, Dion J, Higashida RT, et al. American Heart Association Stroke Council; Council on Cardiovascular Radiology and Intervention; Council on Cardiovascular Nursing; Council on Cardiovascular Surgery and Anesthesia; Council on Clinical Cardiology. Guidelines for the management of aneurysmal subarachnoid hemorrhage: a guideline for healthcare professionals from the American Heart Association/American Stroke Association. Stroke 2012;43:1711-37.

21. Geeraerts T, Velly L, Abdennour L, Asehnoune K, Audibert G, Bouzat P, et al. French Society of Anaesthesia; Intensive Care Medicine; in partnership with Association de neuro-anesthesie-reanimation de langue française; French Society of Emergency Medicine (Societe Francaise de neurochirurgie); Groupe francophone de reanimation et d'urgences pédiatriques; Association des anesthesistes-reanimateurs pediatriques d'expression française. Management of severe traumatic brain injury (first 24 hours). Anaesth Crit Care Pain Med. 2018;37:171-86.

22. Powers WJ, Rabinstein AA, Ackerson T, Adeoye OM, Bambakidis NC, Becker K. American Heart Association Stroke Council. 2018 guidelines for the early management of patients with acute ischemic stroke: a guideline for healthcare professionals from the American Heart Association/American Stroke Association. Stroke. 2018;49:e46-110.

23. Anderson CS, Arima H, Lavados P, Billot L, Hackett ML, Olavarria W, et al. HeadPoST Investigators and Coordinators. Cluster-randomized, crossover trial of head positioning in acute stroke. N Engl J Med. 2017;376:2437-47.

24. Jiang Y, Ye Z, You C, Hu X, Liu Y, Li H, et al. Systematic review of decreased intracranial pressure with optimal head elevation in postcraniotomy patients: a meta-analysis. J Adv Nurs. 2015;71:2237-46.

25. Klarica M, Rados M, Erceg G, Petosic A, Jurjevic I, Oreskovic D. The influence of body position on cerebrospinal fluid pressure gradient and movement in cats with normal and impaired craniospinal communication. PLoS ONE. 2014;9:e95229.

26. Magnaes B. Body position and cerebrospinal fluid pressure. Part 1: clinical studies on the effect of rapid postural changes. J Neurosurg. 1976;44:687-97.

27. Demura S, Yamaji S, Kitabashi T, Yamada T, Uchiyama M. Effects of room temperature and body position change on cerebral blood volume and center-of-foot pressure in healthy young adults. J Physiol Anthropol. 2008;27:63-70.

28. Parichay PJ, Khanapure K, Joshi KC, Aniruddha TJ, Sandhya M, Hegde AS. Clinical and radiological assessment of cerebral hemodynamics after cranioplasty for decompressive craniectomy - a clinical study. J Clin Neurosci. 2017:42:97-101.

29. Martin NA, Patwardhan RV, Alexander MJ, Africk CZ, Lee JH, Shalmon E, et al. Characterization of cerebral hemodynamic phases following severe head trauma: hypoperfusion, hyperemia, and vasospasm. J Neurosurg. 1997:87:9-19. 